\title{
ЛАЗЕРНОЕ СТРУКТУРИРОВАНИЕ АНСАМБЛЯ УГЛЕРОДНЫХ НАНОТРУБОК ДЛЯ СОЗДАНИЯ БИОСОВМЕСТИМЫХ УПОРЯДОЧЕННЫХ КОМПОЗИЦИОННЫХ МАТЕРИАЛОВ
}

\author{
C2017 А. Ю. Герасименко \\ Нацуиональный исследовательский университет «МИЭТ», пл. Шокина, 1, г. Зеленоград, 124498 Москва, Россия \\ e-mail: gerasimenko@bms.zone
}

Поступила в редакцию 04.08.2017

\begin{abstract}
Аннотация. Изложены результаты создания и исследования свойств композиционных материалов, полученных при лазерном нагреве водно-альбуминовой дисперсии однослойных углеродных нанотрубок (ОУНТ) до образования устойчивого твердого состояния. Методом молекулярной динамики показана возможность образования внутреннего упрочняющего каркаса из ансамбля ОУНТ путем их связывания в местах дефектов под действием лазерного нагрева до температуры 80-100 ${ }^{\circ} \mathrm{C}$. На основе анализа спектра комбинационного рассеяния композиционного материала описан процесс связывания атомов кислорода аминокислотных остатков альбумина с атомами углерода ОУНТ. С помощью сканирующей электронной и атомно-силовой микроскопии исследована внутренняя структура и поверхность композиционных материалов, размер пор в которых находится в диапазоне 30-120 нм.
\end{abstract}

Ключевые слова: лазерное излучение, структурирование, каркас, углеродные нанотрубки, дефекты, композиционные материалы, альбумин, биосовместимость.

\section{ВВЕДЕНИЕ}

В области нанотехнологий одну из ключевых ролей играет углерод, который как индивидуальный химический элемент был зарегистрирован А. Л. Лавуазье в конце XVIII века. По сей день происходят открытия новых наночастиц на основе аллотропных модификаций углерода. Одним из перспективных типов углеродных частиц являются нитевидные структуры - углеродные нанотрубки (УНТ). Они привлекают большое внимание исследователей из различных областей науки и техники благодаря своей высокой механической прочности, превосходным тепловым и электрическим свойствами [1]. На основе УНТ проектируют функциональные наноматериалы путем функционализации нанотрубок различными химическими группами и при их взаимодействии с органическими молекулами $[2,3]$.

Существует большое количество работ, описывающих исследования механизмов взаимодействия излучения с углеродными нанотрубками, для выявления линейных и нелинейных оптических эффектов с целью построения новых приборов на их основе [4-6]. Одно из первых указаний на процесс воздействия лазерного излучения на углеродные нанотрубки с целью получения новых каркасных материалов содержится в [7], где использовалось непрерывное излучение $\mathrm{CO}_{2}$ лазера с плотностью мощности $3 \cdot 10^{4} \mathrm{BT} / \mathrm{cm}^{2}$ для создания каркасной морфологии МУНТ в фенольной смоле. В [8] показана возможность механического вращения УНТ при их возбуждении циркулярно поляризованным ИК излучением, распространяющимся вдоль нанотрубок. Момент инерции нанотрубки составил 28 ГГц, а центробежное ускорение на поверхности трубки $0.5 \cdot 10^{12} \mathrm{M} / \mathrm{c}^{2}$. Это значение на 2-5 порядков больше, чем создают быстрейшие центрифуги, однако изза малости результирующей силы на каждом атоме углерода оно пренебрежимо по сравнению с действием обычной молекулярной силы связи.

С использованием УФ импульсного лазерного излучения (длина волны генерации $\lambda_{\text {ген }}=248$ нм, длительность импульсов $\tau=25$ нс, частота повторения импульсов $f=10$ Гц) для испарения композиционной мишени на основе УНТ в матрице толуола удалось переместить, иммобилизировать и фиксировать нанотрубки с заданной сетеобразной морфологией на стеклянной подложке [9]. При постепенном увеличении плотности мощности действующего на УНТ лазерного излучения получено 
контролируемое введение дефектов в их структуру [10]. Дефекты УНТ могли быть местами связывания нанотрубок в упорядоченную сеть.

В последнее время появляется все больше статей, описывающих способы применения УНТ в биомедицинской инженерии тканей и органов. Нанотрубки используются в качестве каркасной структуры композиционных материалов для замещения дефектных полостей биологических тканей, поскольку могут улучшить механические свойства и биосовместимость жидких дисперсных сред и твердых композитов $[11,12]$. УНТ имеют размеры, близкие к размерам основных компонентов природного клеточного матрикса, а их механические свойства подобны свойствам протеиновых структур живого организма. Нанотрубки способны имитировать фибриллярный белок коллаген внеклеточного матрикса ввиду периодически повторяющихся дефектов в структуре УНТ, схожей со структурой коллагена [13].

Для создания биологических композиционных материалов используются многослойные (МУНТ) и однослойные (ОУНТ) углеродные нанотрубки, включенные в полимерные матрицы из поликапролактона, хитозана, полилактида, гидроксиапатита и т. д. [14-18]. Применение композиционных материалов на основе УНТ в инженерии биологических тканей обеспечивает улучшение показателей развития клеток: их адгезии, пролиферации и дифференцировки.

В работе [15] описано создание нанокомпозитов на основе МУНТ и поликапролактона путем выпаривания исходной диспергированной ультразвуком дисперсии. Механические характеристики при добавлении МУНТ были существенно увеличены. Модуль упругости при сжатии нанокомпозитов с концентрацией МУНТ 0.5-2 мас.\% увеличился на $37.2-54.5 \%$, соответственно, по сравнению с чистым поликапролактоном. Анализ адгезии клеток костного мозга крыс при их посеве на образцы показал, что клетки занимали всю поверхность нанокомпозита и только 60 \% поверхности чистого поликопролактона, что может быть обосновано топографией поверхности нанокомпозитных каркасов. В этой же работе установлено, что нанокомпозиты, содержащие 0.5 мас.\% МУНТ, вызывали наибольшее усиление пролиферации и дифференцировки клеток костного мозга, в то время как при содержании МУНТ более 2 мас.\% в составе образцов приводило к снижению роста клеток.

Помимо изготовления композиционных материалов методом введения УНТ в биополимерные матрицы активно ведутся работы по созданию каркасов из нанотрубок, функционализированных биосовместимыми веществами, например, хитозаном [19]. Разработана серия нанокомпозитных каркасов для инженерии костной ткани. По сравнению с каркасами из чистого хитозана с пористостью $87.7 \%$, добавление 0.01 мас.\% функционализированных МУНТ (ф-МУНТ) увеличило пористость до $88.5 \%$, вероятно, из-за высокой удельной площади поверхности ф-МУНТ. На каркасах ф-МУНТ наблюдалась вдвое большая пролиферация клеток, чем на чистом хитозане. Авторы объясняют данные результаты способностью ф-МУНТ благоприятно взаимодействовать с клетками и успешно поддерживать их метаболические функции. В следующей работе авторов приведены результаты регенерации костной ткани на композитах из гидроксиапатита с добавлением ф-МУНТ [17].

В работе [20] был получен синтетический костный каркас на основе коротких УНТ с длиной 2080 нм в биоразлагаемой матрице. Биологические исследования таких материалов позволили получить увеличение площади кости на $300 \%$ по сравнению с матрицей без нанотрубок. При этом дефект костной ткани был полностью замещен ростом ткани организма в процессе разложения имплантата. А с использованием карбоксилированных ОУНТ (COOH-ОУНТ), напыленных на покровные стекла, были продемонстрированы ускоренная дифференцировка и развитие стволовых клеток предшественников остеобластов (клеток костной ткани) [21]. Также авторы использовали данные ОУНТ как связующую добавку в комбинацию деминерализованной костной матрицы или частиц хряща для создания человеческих аллотрансплантатов. В результате этого была обнаружена высокая проницаемость и связность пор в имплантатах с нанотрубками, в сформированной ткани появились многочисленные каналы васкуляризации с новыми сосудами. В исследовании [22] получали биокаркасы из вертикально ориентированных углеродных нанотрубок в смеси наночастиц гидроксиапатита и полимолочной кислоты методом электроосаждения. Хотя биосовместимость и цитотоксичность УНТ не выяснены до конца, многие исследователи пришли к выводу, что некоторые типы нанотрубок в определенной концентрации могут быть удалены из системного кровообращения путем выведения через почки.

В настоящей работе представлено теоретическое и экспериментальное описание лазерного структурирования ансамбля УНТ для создания 
композиционных материалов с упорядоченной каркасной структурой. Приведены результаты исследования внутренней и поверхностной структуры композиционных материалов, полученных при взаимодействии лазерного излучения с водно-белковой дисперсией нанотрубок.

\section{ЭКСПЕРИМЕНТАЛЬНАЯ ЧАСТЬ}

\section{Методика получения образцов}

Для создания композиционных материалов использовались однослойные углеродные нанотрубки (ОУНТ). Нанотрубки были синтезированы электродуговым методом на $\mathrm{Ni} / \mathrm{Y}$ катализаторе, очищены на воздухе с промывкой $\mathrm{HCl}$ и фукционализированы карбоксильными группами в смеси $\mathrm{HNO}_{3} / \mathrm{H}_{2} \mathrm{SO}_{4}$ с промывкой до нейтральной реакции. Средний диаметр нанотрубок составлял 1.4-1.6 нм, длина 0.3-0.8 мкм, а удельная поверхность продукта равнялась $400 \mathrm{~m}^{2} /$ г. Степень чистоты ОУНТ составляла $97.16 \%$. Химический состав ОУНТ определялся методом рентгенофлуоресцентного анализа с использованием комплекса Shimadzu XRF 1800 (табл. 1). В нанотрубках наблюдалось незначительное количество примесей (остатков катализаторов и др.).

В результате промывки ОУНТ были получены в виде водной пасты с концентрацией 2.5 мас.\%. В исходном состоянии изображение нанотрубок, полученное методом сканирующей электронной

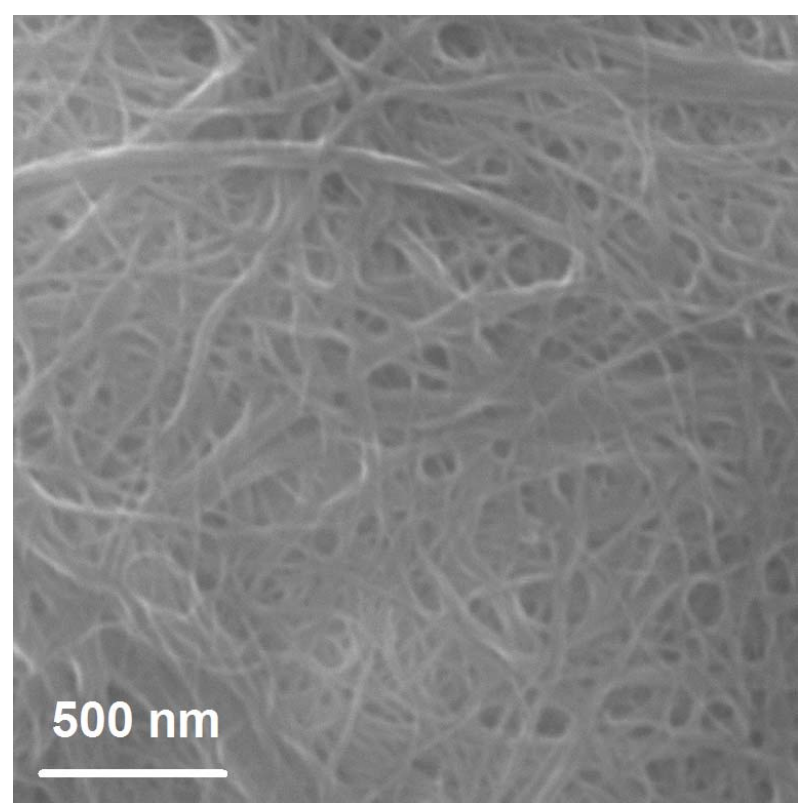

$a$ микроскопии (СЭМ), характеризовалось толстыми пучками ОУНТ диаметром 50-100 нм (рис. 1a). С целью выделения ОУНТ из пучков готовилась водная дисперсия с концентрацией нанотрубок $0.01-$ 1 мас.\%. Далее дисперсия подвергалась мощному ультразвуковому диспергированию с помощью погружного зонда с удельной мощностью $\sim 40 \mathrm{BT} / \mathrm{cm}^{3}$ (рис. $1 b$ ). В результате диспергирования в водной дисперсии присутствовали в основном единичные ОУНТ и их пучки, диаметр которых не превышал 10 нм, что подтверждалось данными рис. $1 b$, полученными методом просвечивающей электронной микроскопии (ПЭМ).

Далее следовало добавление в водную дисперсию ОУНТ порошкообразного белка - альбумина с концентрацией 25 мас.\%. Выбор альбумина в качестве компонента матрицы обусловлен его распространенным использованием в качестве связу-

Таблица 1. Химический состав ОУНТ

[Table 1. Chemical composition of SLCNT]

\begin{tabular}{|c|c|}
\hline $\begin{array}{c}\text { Химический элемент } \\
\text { [Chemical element] }\end{array}$ & $\begin{array}{c}\text { Массовая доля, \% } \\
\text { [Mass fraction, \%] }\end{array}$ \\
\hline $\mathrm{C}$ & 97.16 \\
\hline $\mathrm{Ni}$ & 0.49 \\
\hline $\mathrm{Fe}$ & 0.24 \\
\hline $\mathrm{Cr}$ & 0.33 \\
\hline $\mathrm{Si}$ & 0.40 \\
\hline $\mathrm{Cl}$ & 0.93 \\
\hline
\end{tabular}

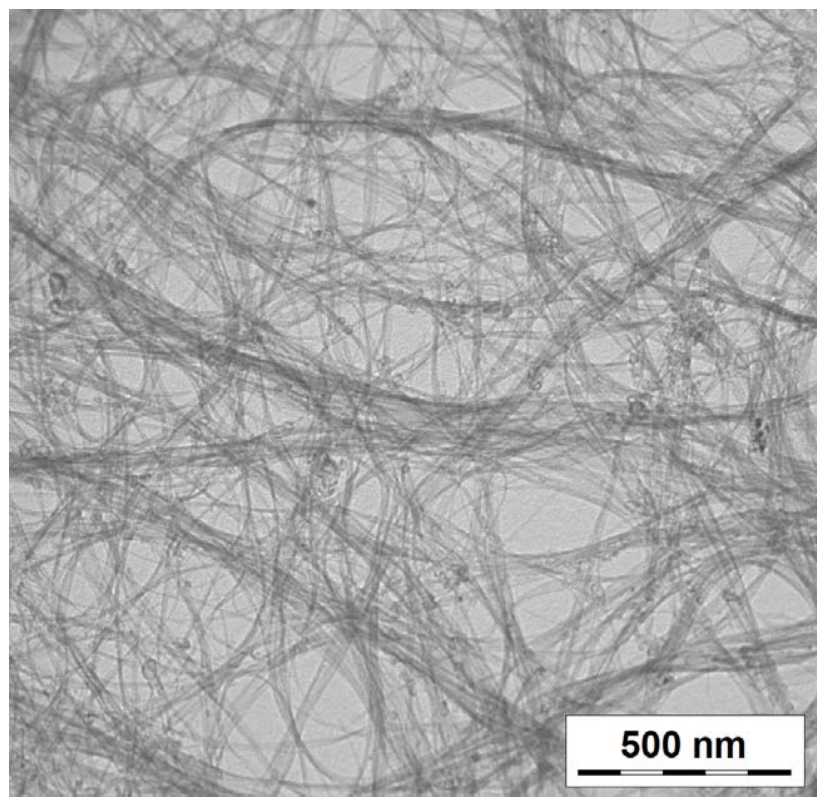

$b$

Рис. 1. Изображения высохшей капли водной дисперсии ОУНТ на кремниевой подложке до $(a)$ и после $(b)$ ультразвукового диспергирования

[Fig. 1. SEM images of an aqueous SLCNT dispersion dried drop on a silicon substrate before $(a)$ and after $(b)$ ultrasonic treatment] 
ющего вещества, наносимого в область раны при лазерном сваривании биологических тканей [23]. Альбумин составляет около $60 \%$ белков плазмы крови, его средняя концентрация в плазме $\sim 40$ г/л. Транспортная функция альбумина состоит в переносе свободных жирных кислот, холестерина и других биологически активных веществ. Для альбумина типична конформация во вторичной или третичной структуре при незначительной загрузке белка токсическими продуктами. Картина высохшей капли свежеприготовленного водного раствора сывороточного альбумина характеризуется наличием значительного количества радиальных трещин, образующих арки по краю капли. Он хорошо изучен на атомарно-структурном уровне: молекула альбумина имеет две модификации (изомеpa), представляющие собой эллипсоид вращения и неправильную треугольную призму [24].

На завершающем этапе приготовления водноальбуминовой дисперсии ОУНТ осуществлялось механическое перемешивание среды с использованием вращающегося магнитного якоря и диспергирование ее в ультразвуковой ванне за равные промежутки времени в течение 40-60 минут.

Особенностью настоящего метода формирования композиционных материалов являлось использование несфокусированного лазерного пучка, который падал на водно-альбуминовую дисперсию ОУНТ (рис. 2a). Формирование твердого материала происходило в результате испарения жидкой компоненты водно-альбуминовой дисперсии ОУНТ лазерным излучением. Использовался непрерывный диодный лазер с длиной волны генерации в ближней области ИК-диапазона - 970 нм. Рабочая мощность излучения лазера колебалась от 1 до 3 Вт и изменялась посредством варьирования силы тока, подаваемой на лазерный диод. Это позволяло осуществить контролируемый нагрев водно-альбуминовой дисперсии ОУНТ до необходимой температуры без разрушения трехмерной структуры молекул альбумина.

Как видно из рис. $2 a$, излучение лазера (1) попадало на набор калиброванных нейтральных светофильтров (2), который использовался для точного варьирования мощности излучения. Далее излучение с помощью светоделительной пластины (3) расщеплялось на две части. Первая часть излучения попадала на детектор мощности (5) через второй набор калиброванных нейтральных светофильтров (4). Вторая часть излучения поворачивалась на угол $90^{\circ}$ призмой (6) и падала на отрицательную линзу (7). Расфокусированное лазерное излучение попадало на объектив (8), где лучу придавался необходимый диаметр для воздействия на водно-альбуминовую дисперсию ОУНТ (10) в сосуде (9). Излучение имело пространственный профиль с гауссовым распределением (11). Диаметр падающего пучка был равен диаметру емкости с водноальбуминовой дисперсией УНТ ( 5 мм). Толщина слоя облучаемой дисперсии составляла $\sim 5$ мм. Воздействие лазерного излучения на дисперсию осуществлялось до формирования композиционного материала в твердом фазовом состоянии. Размеры и форма материала напрямую зависят от формы емкости, в которой находится дисперсия ОУНТ. В эксперименте получался композиционный материал в виде образца цилиндрической формы высотой $\sim 4$ мм, диаметром $\sim 5$ мм (рис. $2 b$ ). Помимо получения описанных выше объемных композиционных материалов с использованием данной

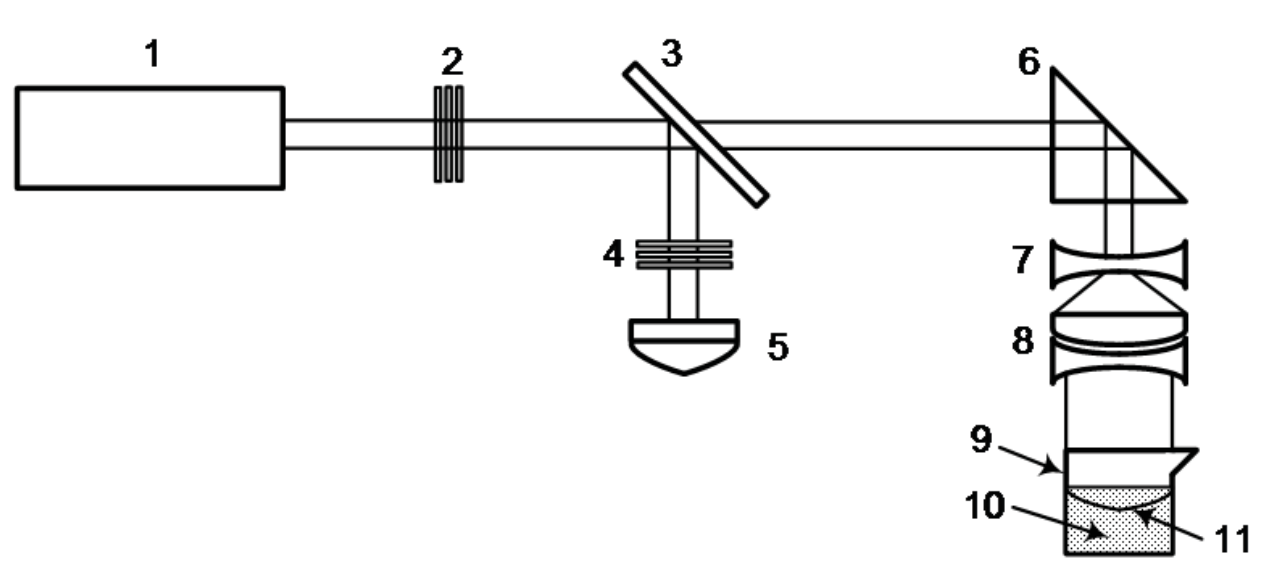

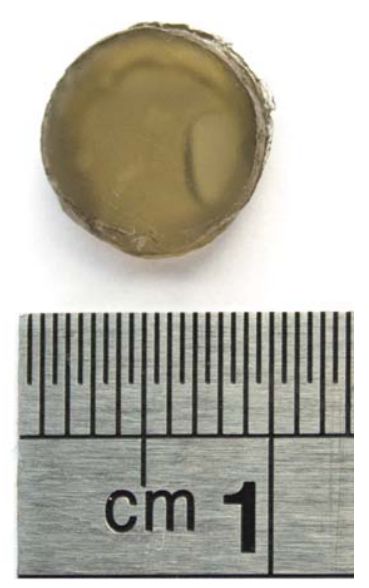

$b$

Рис. 2. Оптическая схема установки ( $a$ ) для изготовления композиционных материалов $(b)$

[Fig. 2. Optical scheme of the installation diagram $(a)$ for the creation of composite materials $(b)$ ] 
технологии можно получать и пленочные образцы нанокомпозитов.

\section{РЕЗУЛЬТАТЫ И ИХ ОБСУЖДЕНИЕ}

\section{Моделирование образования композиционных материалов}

Моделирование механизма изготовления композиционных материалов проводилось с позиции формирования каркаса из ансамбля ОУНТ при его взаимодействии с лазерным излучением с использованием методик молекулярной динамики. Как известно, углеродные нанотрубки содержат многочисленные дефекты, образующиеся в ходе их синтеза, а разогрев лазерным лучом областей ОУНТ с дефектами будет осуществляться сильнее, поскольку теплопроводность в этих участках ниже, чем в бездефектных $[25,26]$. Таким образом, наиболее вероятными областями связывания нанотрубок будут именно дефектные участки.

В работе рассмотрены две нанотрубки с индексами хиральности $(22,22)$ и $(24,24)$, так как их диаметры близки по величине к обычно используемым в эксперименте ОУНТ и составляют 1.4 и 1.6 нм соответственно. В качестве дефектов моделировались часто встречающиеся - дефекты единичной вакансии $(1 \mathrm{~V})$, двойной вакансии $(2 \mathrm{~V})$ и Стоуна-Уэлса (SW).

В начальный момент времени моделирования нанотрубки произвольным образом располагались в периодическом ящике водной среды. Температура увеличивалась до 90-200 ${ }^{\circ} \mathrm{C}$ с использованием термостата Нозе-Гувера. Энергия нанотрубок рассчитывалась с помощью силового поля Reactive Empirical Bond Order Potential [27]. Моделирование процесса образования С-С связей между нанотрубками, содержащими дефекты, осуществлялось в течение нескольких наносекунд.

На рис. 3 представлены результаты серии численных экспериментов - фрагменты каркаса из УНТ, сформированного при связывании открытого конца трубки $(22,22)$ с дефектной областью трубки $(24,24)$. На рис. 3 представлены четыре варианта контакта: при наличии в атомной структуре ОУНТ $(24,24)$ одного дефекта типа $2 \mathrm{~V}(a)$, двух $(b)$ и трех (c) дефектов $2 \mathrm{~V}$, а также при наличии сразу нескольких видов дефекта - двух дефектов типа $2 \mathrm{~V}$ и одного SW $(d)$. Были рассмотрены и другие концентрации дефектов, а также и такой дефект как единичная вакансия атома углерода (1V).

В процессе связывания ОУНТ рассчитывалась энтальпия формирования контакта. На рис. $4 a$ показаны графики изменения энтальпии формирова- ния химических связей от их количества для различных вариантов дефектных областей. В каждом случае дефектная область содержала разное количество дефектов (1V, $2 \mathrm{~V}$ и $\mathrm{SW})$. Графики энтальпии позволяют сделать вывод, что энергетически наиболее выгодным является процесс формирования каркаса из ОУНТ при наличии в области связывания нанотрубок четырех дефектов типа $1 \mathrm{~V}$. Длины C-C связей между трубками находятся в диапазоне от 1.38 до $1.55 \AA$.

Термодинамическая устойчивость полученных связываний ОУНТ была проверена с помощью молекулярного динамического моделирования (до 2 нс) при увеличении температуры до 600 К и далее до 1200 К. Установлено, что образовавшиеся ковалентные связи нанотрубочного каркаса сохраняются при разогреве лазерным лучом даже до 1200 К. С целью верификации полученных результатов фрагмент с контактами нанотрубочного каркаса был исследован методом функционала плотности на базе схемы сильной связи (DFTB2) [28]. Атомная структура связанных нанотрубок оптимизировалась методом DFTB2. Исследование атомной структуры подтвердило полученную топологию области контакта нанотрубок с сохранением тех же С-С связей между ОУНТ.

Таким образом, были выявлены решающие факторы образования нанотрубочного каркаса под действием лазерного нагрева: расстояние между дефектным участком нанотрубки и открытым концом другой нанотрубки; температура лазерного нагрева. Увеличение температуры уже до $80-100{ }^{\circ} \mathrm{C}$ инициирует появление $\mathrm{C}-\mathrm{C}$ связей, поскольку локальный разогрев дефектных областей приводит к увеличению амплитуды колебаний атомов и, как следствие, к формированию С-С связей. Дальнейшее увеличение температуры может незначительно увеличить количество С-С связей, но при этом и разрушить некоторые связи, особенно на сильно деформированных участках. Тот есть, в целом, большие значения температуры не принципиальны для процесса образования нанотрубочного каркаса.

На основании численного моделирования было установлено среднее время непосредственного образования связей между нанотрубками на расстоянии 2-2.5 А. Это время составляет 10-20 пс в зависимости от количества образовывающихся химических связей. На рис. $4 b$ показано изменение количества С-С связей с течением времени при образовании контакта нанотрубок для случая смешанных дефектов в структуре ОУНТ (рис. 3d). Хорошо виден характер формирования сцепления 


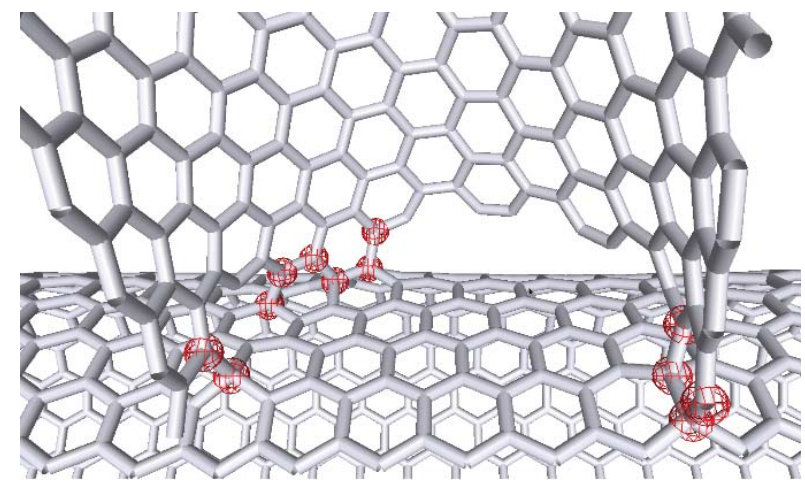

$a$

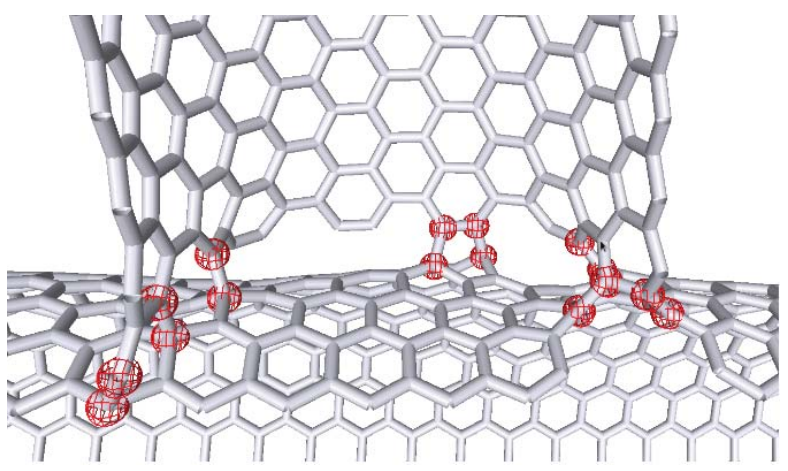

c

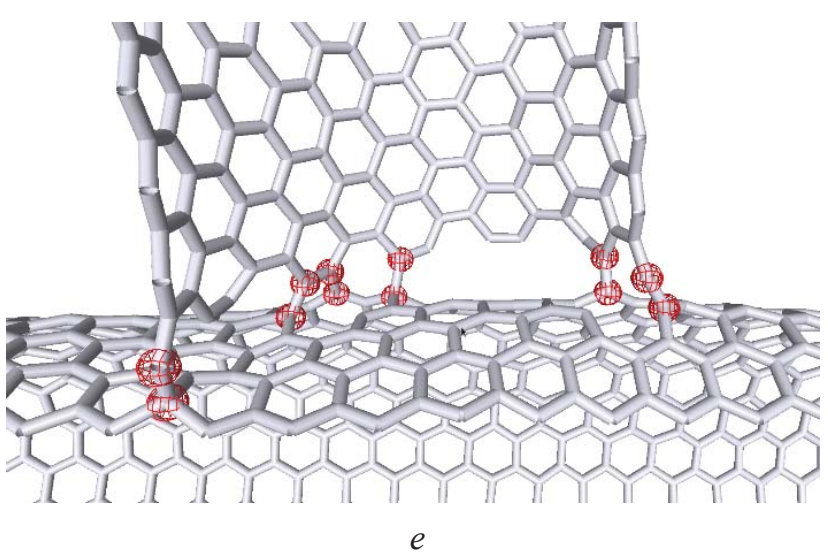

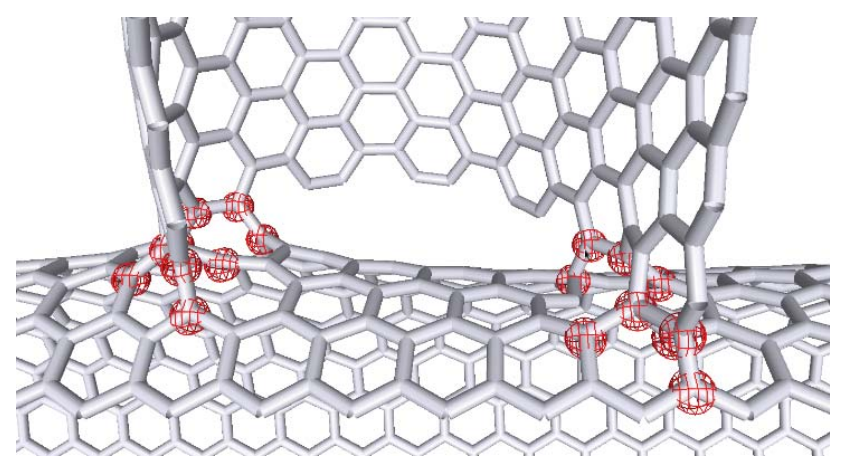

$b$
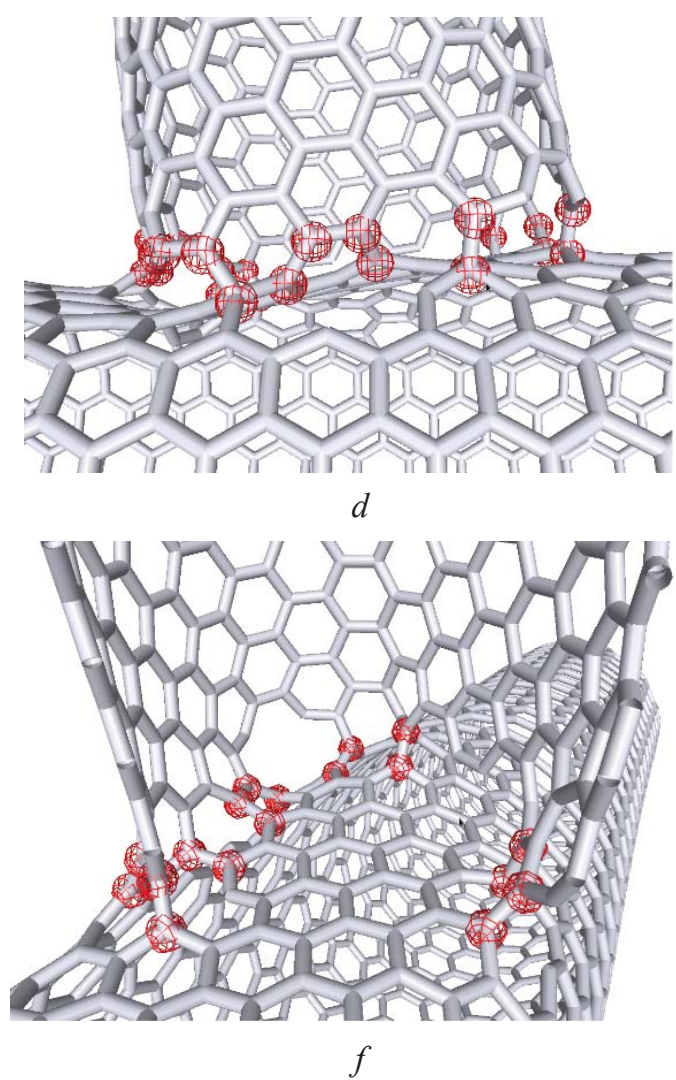

Рис. 3. Фрагменты каркаса из ОУНТ при наличии в них дефектов вакансий углерода: один $2 \mathrm{~V}(a)$, два $2 \mathrm{~V}(b)$, три $2 \mathrm{~V}(c)$, один $2 \mathrm{~V}$ и один $\mathrm{SW}(d)$, три $1 \mathrm{~V}(e)$ и четыре $1 \mathrm{~V}(f)$

[Fig. 3. Fragments of SLCNT framework in the presence of carbon vacancy defects: one $2 \mathrm{~V}(a)$, two $2 \mathrm{~V}(b)$, three $2 \mathrm{~V}(c)$, one $2 \mathrm{~V}$ and one SW $(d)$, three $1 \mathrm{~V}(e)$ and four $1 \mathrm{~V}(f)]$

нанотрубок. Выяснено, что под действием лазерного нагрева могут образовываться сразу две и более связи, затем разрушаться и снова появляться. Однако в течение короткого времени все связи стабилизируются.

\section{Сканирующая электронная микроскопия композиционных материалов}

Экспериментальные данные исследования механических характеристик композиционных материалов демонстрируют высокие значения твердости 270-330 МПа, что указывает на образование ко- валентных связей в местах связывания нанотрубок. На рис. 5 представлены изображения СЭМ композиционного материала. Для рассмотрения каркасной структуры была выбрана трещина в образце (рис. 5a) и под углом 52॰ получено изображение поперечного сечения трещины композиционного материала (рис. 5b).

На изображении СЭМ видно увеличение диаметра ОУНТ от 1.4-1.6 нм (рис. 1b) до 30-40 нм (рис. 5b). Это может быть связано со слипанием ОУНТ в пучки под действием сил Ван-дер-Вааль- 

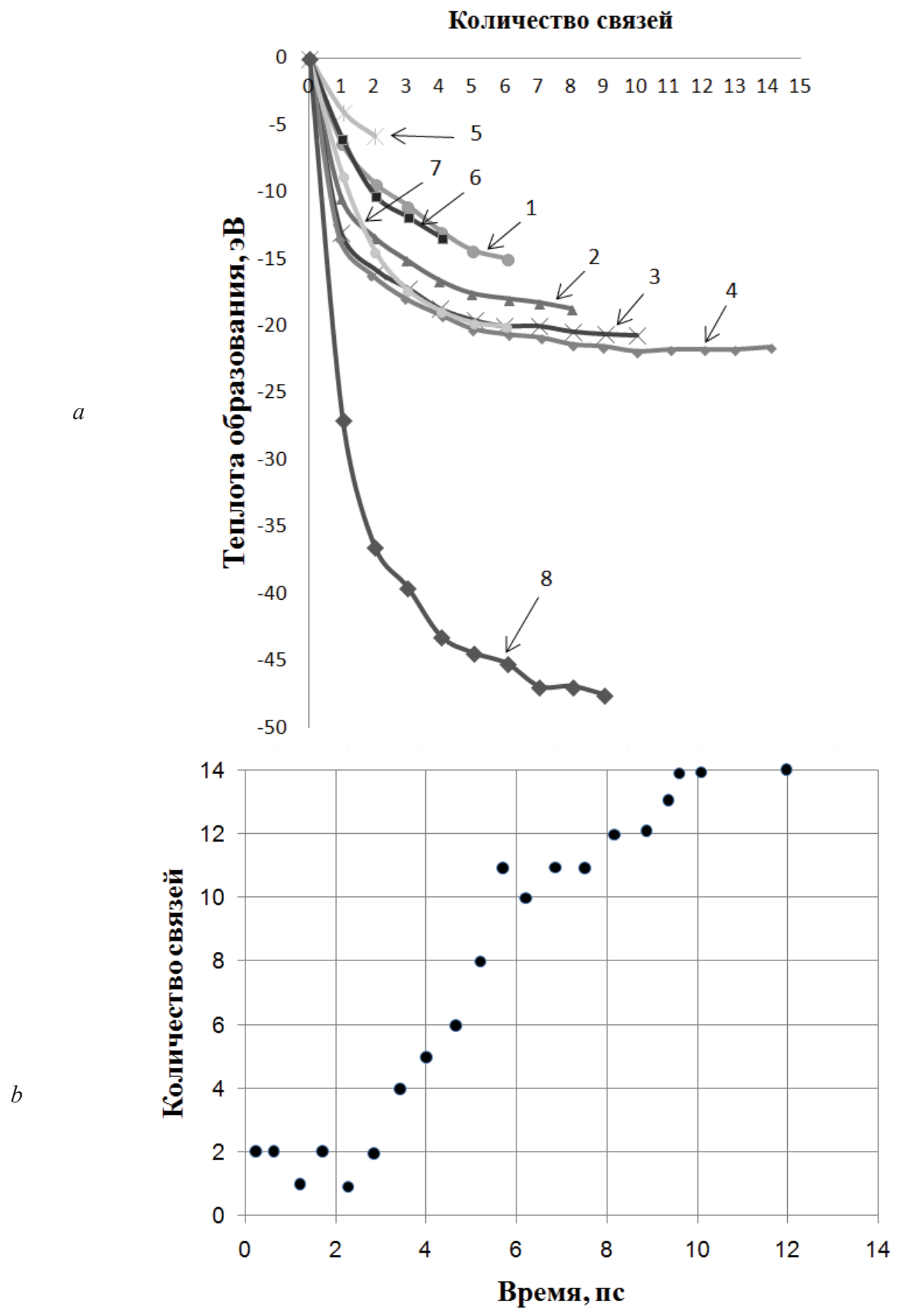

Рис. 4. Графики изменения энтальпии ( $a$ ) формирования каркаса из ОУНТ при наличии дефектов: кривая 1 - один $2 \mathrm{~V}$, кривая 2 - два $2 \mathrm{~V}$, кривая 3 - три $2 \mathrm{~V}$, кривая 4 - два $2 \mathrm{~V}$ и один $\mathrm{SW}$, кривая 5 - один $1 \mathrm{~V}$, кривая 6 - два $1 \mathrm{~V}$, кривая 7 - три $1 \mathrm{~V}$, кривая 8 - четыре $1 \mathrm{~V}$; процесс изменения количества $\mathrm{C}-\mathrm{C}$ связей во времени при образовании контакта нанотрубок для случая смешанных дефектов в структуре ОУНТ (b)

[Fig. 4. Graphs of the enthalpy change (a) of the formation of the SLCNT framework with defects: curve 1-one 2V, curve 2 - two $2 \mathrm{~V}$, curve 3 - three $2 \mathrm{~V}$, curve 4 - two $2 \mathrm{~V}$ and one $\mathrm{SW}$, curve 5 - one $1 \mathrm{~V}$, curve 6 - two $1 \mathrm{~V}$, curve 7 - three $1 \mathrm{~V}$, curve 8 - four $1 \mathrm{~V}$; the process of changing the number of C-C bonds in time with the formation of a nanotubes contact for the case of mixed defects in the structure of $\operatorname{SLCNT}(b)]$ 


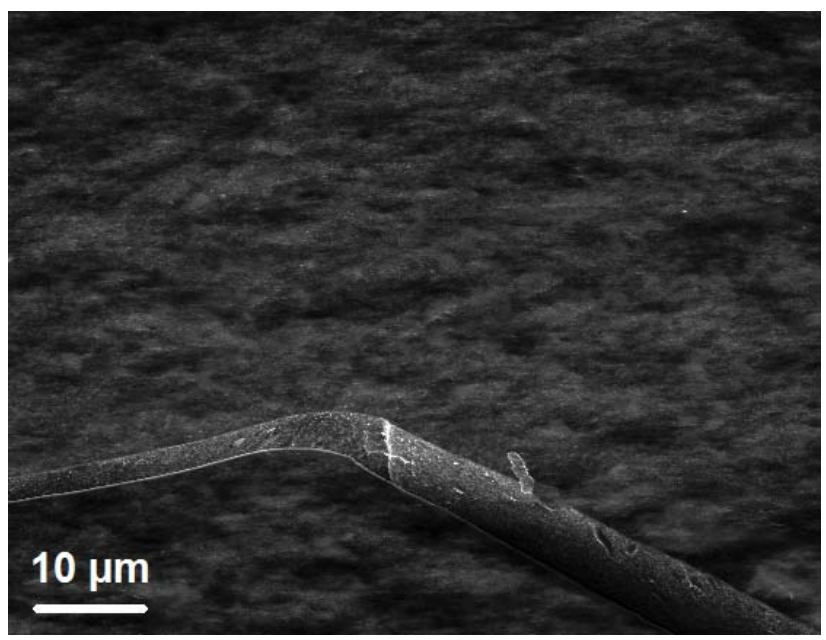

$a$

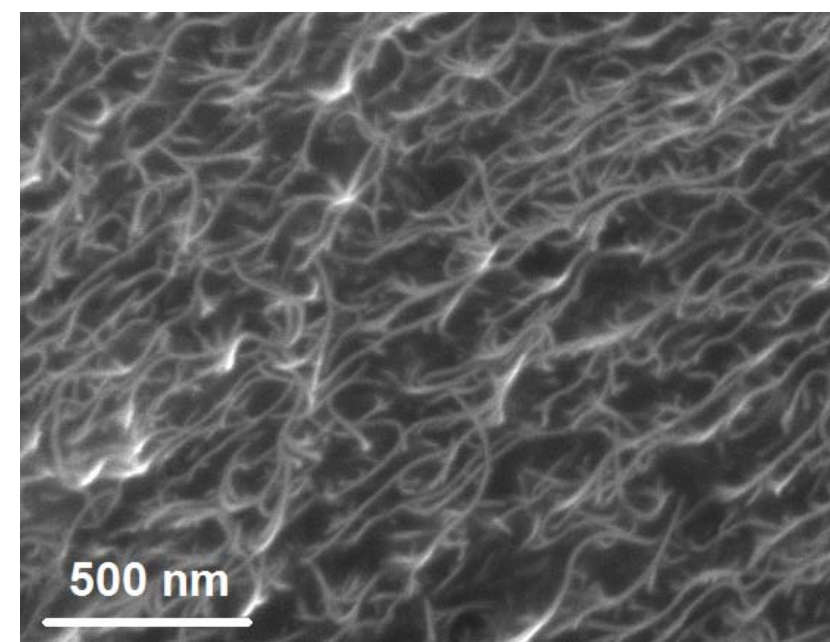

$b$

Рис. 5. Изображения СЭМ композиционного материала на кремниевой подложке с трещиной $(a)$ и поперечного сечения трещины $(b)$

[Fig. 5. SEM images of a composite material on a silicon substrate with a crack $(a)$ and a cross-section of crack $(b)$ ]

са. Однако из изображения ПЭМ исходных ОУНТ можно заметить иной вид нанотрубочных пучков. Другой причиной увеличения диаметра ОУНТ является функционализация ОУНТ слоем альбумина в процессе образования композиционных материалов под действием лазерного нагрева. Наблюдалось образование разветвленной древовидной структуры.

\section{Спектроскопия комбинационного рассеяния композиционных материалов}

Образование композиционных материалов с позиции связывания аминокислотных остатков белка альбумина с ОУНТ описывалось с помощью спектроскопии комбинационного рассеяния (КР). Спектр, возбуждаемый излучением Nd:YAG лазе- pa $\left(\lambda_{\text {ген }}=1.046\right.$ мкм, мощность $N=0.1-0.2$ Вт), записывался с разрешением $4 \mathrm{~cm}^{-1}$, усреднялся по 150 сканам и подвергался обратному Фурье преобразованию (рис. 6).

На спектре практически не видны пики валентных О-Н колебаний молекул воды $\left(3283 \mathrm{~cm}^{-1}\right)$, которые в спектроскопии КР выражены неярко и размыты. Ярко выражен пик $2932 \mathrm{~cm}^{-1}$ валентных симметричных колебаний $\mathrm{CH}_{2}$, который характерен для всех органических соединений. Присутствует пик $1673 \mathrm{~cm}^{-1}$ - амид I (валентное $\mathrm{C}=\mathrm{O}$ колебание), который проявляется почти для всех белковых макромолекул. Низкая интенсивность пика свидетельствует о небольшой доле альбумина в конформации $\alpha$-спирали. $1003 \mathrm{~cm}^{-1}-$ пик соответ-

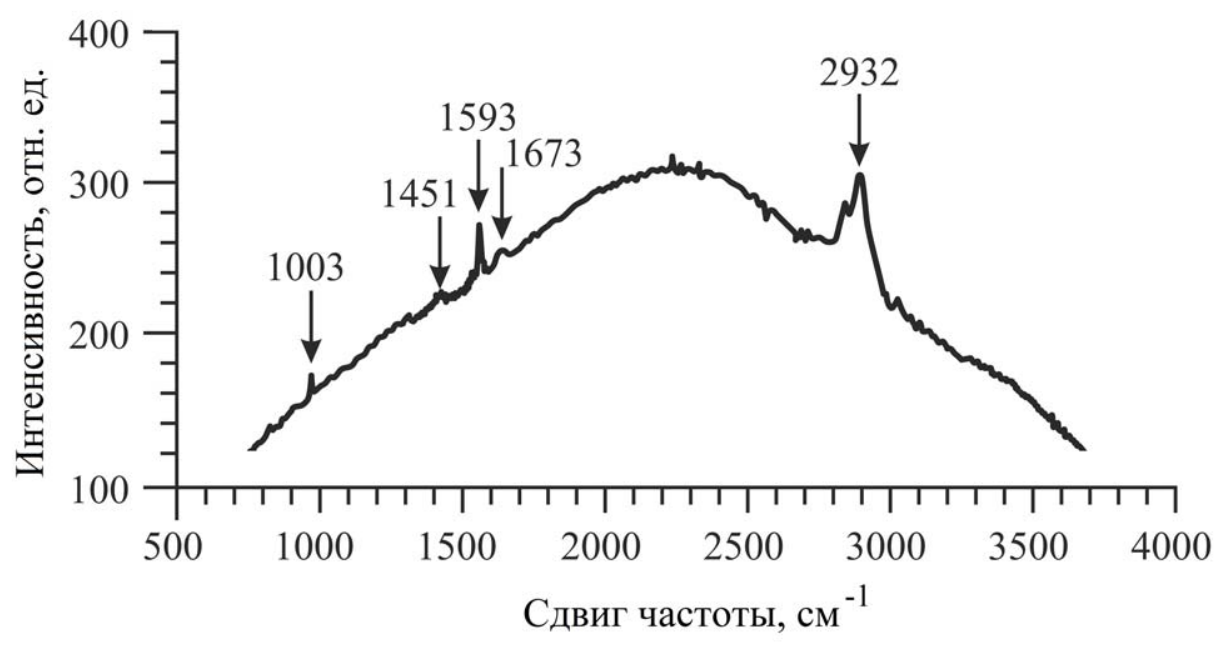

Рис. 6. Спектр КР композиционного материала

[Fig. 6. Raman spectrum of a composite material] 
ствует $\mathrm{C}-\mathrm{C}$ валентным колебаниям ароматических органических соединений.

Кроме деформационных колебаний $\mathrm{CH}_{3}$ и $\mathrm{CH}_{2}$ $\left(1443,1335 \mathrm{~cm}^{-1}\right)$ в спектрах композиционного материала выявлена полоса, характеризующая органическую составляющую $-1593 \mathrm{~cm}^{-1}$. Этот пик соответствует валентным колебаниям (ССH) ароматического кольца. Невысокая выраженность колебаний амид I, означающая низкую долю белковой составляющей в конформации $\alpha$-спирали, объясняется частичной денатурацией альбумина при лазерном воздействии в процессе создания композиционного материала. Интересно отметить снижение интенсивности пика колебания на $1593 \mathrm{~cm}^{-1}$, характерного для ОУНТ. По-видимому, в ходе получения образца воздействие лазерного излучения и связывание с белком приводит к возникновению материала со структурой, отличной от чистых ОУНТ.

Из спектра КР композиционного материала были определены аминокислотные остатки Glu и Asp на поверхности альбумина, взаимодействующие с ОУНТ. В радикале кислых аминокислот имеется дополнительная карбоксильная группа, которая может образовывать химическую связь через атомы кислорода с поверхностью ОУНТ. При моделировании взаимодействия альбумина с ОУНТ была рассчитана энергия взаимодействия, диапазон значений которой составлял от 3.7 до 580 кДж/моль. Нижняя граница данного диапазона соответствует энергиям Ван-дер-ваальса для межмолекулярного взаимодействия аминокислот в бел-

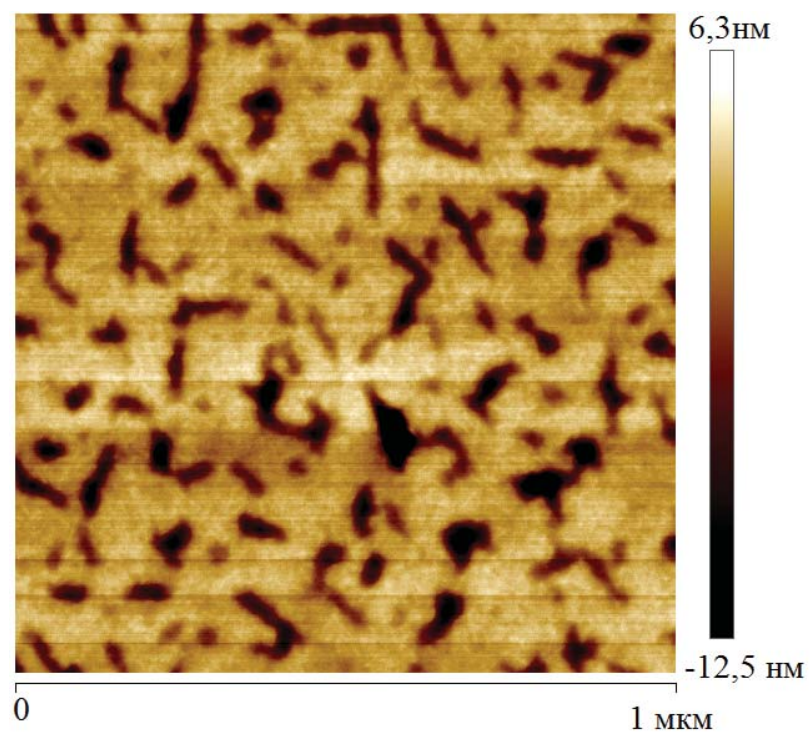

$a$ ках, а верхняя - энергии ковалентной связи между молекулой углерода нанотрубки и кислородом аминокислотных остатков альбумина [29].

\section{Атомно-силовая микроскопия композиционных материалов}

С использованием атомно-силовой микроскопии (AСМ) получена топография поверхности образцов на кремниевой подложке (рис. 7). На рис. $7 a$ наблюдаются срезы пор с размерами от 30 до 120 нм (темные пятна). Вид и количество пор зависели от технологических параметров приготовления образцов (концентрации ОУНТ, времени и мощности лазерного воздействия). При увеличении в исходной дисперсии альбумина концентрации ОУНТ, количество пор и их размер уменьшались. Это может быть связано с армирующим действием ОУНТ при образовании каркаса под действием лазерного излучения.

Трехмерный вид изображения АCM композиционного материала на основе ОУНТ демонстрировал низкие $(-11$ нм) и высокие (+6 нм) участки образцов (рис. $7 b)$. Структура поверхности наблюдалась достаточно равномерной с периодически повторяющимися углублениями в виде пор.

\section{ЗАКЛЮЧЕНИЕ И ВЫВОДЫ}

При лазерном облучении в ближней ИК области спектра водно-альбуминовой дисперсии ОУНТ происходит интенсивное поглощение излучения, которое сопровождается нагревом нанотрубок. Как известно, УНТ обладают высокой теплопроводно-

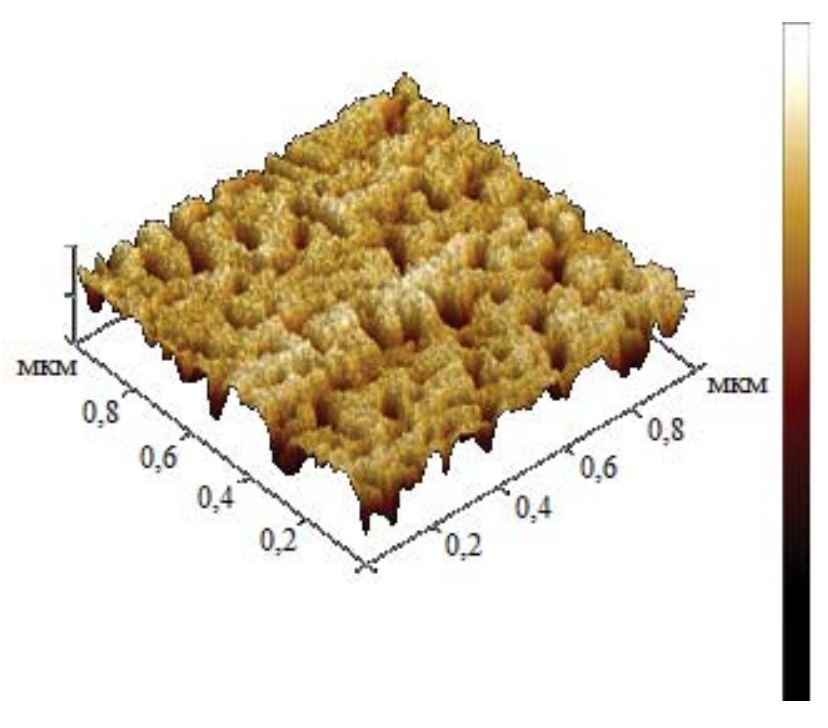

$b$

Рис. 7. Изображения АСМ композиционного материала, вид сверху $(a)$ и трехмерный вид $(b)$

[Fig. 7. AFM images of a composite material, top view $(a)$ and three-dimensional view $(b)$ ] 
стью и эластичностью, что позволяет им даже при очень сильном разогреве не разрушаться, а распределять тепловую энергию по всей длине. Тем не менее, значительный разогрев может наблюдаться на концах нанотрубки и в локальных областях дефектов, где теплопроводность ниже. Дефекты различного рода в нанотрубках возникают в ходе их синтеза и при нагреве лазерным излучением. Поскольку химически наиболее активными являются открытые концы нанотрубок и области с дефектами, за основу была взята идея о связывании ОУНТ именно в дефектных областях. Численное моделирование показало, что уже при нагреве лазерным лучом до температуры - 80-100 ${ }^{\circ} \mathrm{C}$ начинается процесс связывания ансамбля нанотрубок в каркасную структуру. Этот процесс протекает в течение нескольких наносекунд. При увеличении температуры до больших значений, например до 1200 К, процесс образования нанотрубочных контактов протекает быстрее, за 10-12 пс. Важным моментом является установленный факт того, что сформировавшийся нанотрубочный каркас не разрушается при нагреве до 1200-1400 К, сохраняя свою термодинамическую стабильность.

В композиционных материалах связывание ОУНТ с молекулами альбумина происходит через аминокислотные остатки Glu и Asp. Такая связь появляется между атомами углерода ансамбля нанотрубок и атомами кислорода аминокислотных остатков альбумина. Результаты молекулярного динамического моделирования позволили выяснить, что увеличение числа атомов кислорода приводит к уменышению энергии взаимодействия между ОУНТ и альбумином. Присоединение атома кислорода к ОУНТ приводит к деформации нанотрубки и чем больше атомов кислорода, тем сильнее деформация. Изменяя точки присоединения атома кислорода к атомам углерода нанотрубки, возможно задавать необходимую конфигурацию (форму) нанотрубочного каркаса в матрице альбумина. Это в свою очередь будет определять условия регенерации клеток тех или иных биологических тканей.

Композиционные материалы на основе водноальбуминовой дисперсии ОУНТ имеют развитую поверхность с периодически повторяющимися возвышенностями и впадинами. Это видно из топографии поверхности изображений АСМ и связано с появлением углеродного нанотрубочного каркаса, сформированного лазерным излучением.

Описанные композиционные материалы за счет своей структуры и состава могут обеспечить улучшенную адгезию клеток, высаженных на их повер- хность. В связи с этим из них, возможно, удастся создавать тканеинженерные матрицы для восстановления трехмерной структуры костной и соединительной ткани живого организма.

Автор выражает благодарность профессору, д.ф.-м.н. Подгаеикому В.М. и научному коллективу кафедры биомедицинских систем МИЭТ за помощь в проведении экспериментальных работ и обсуждении результатов, а также научному коллективу профессора, д.ф.-м.н. Глуховой О.Е. за помощь в проведении теоретических исследований, в том числе с использованием программного продукта KVAZAR (www.nanokvazar.ru).

Работа выполнена при поддержке гранта Президента Российской Федераџии 14.Y30.17.1328-МК от 22 февраля 2017 г.

\section{СПИСОК ЛИТЕРАТУРЫ}

1. Елецкий А. В. // Успехи физических наук, 1997, т. 167, № 9, с. 945-972.

2. Тучин А. В., Тяпкина В. А., Битюцкая Л. А., Бормонтов Е. Н. // Конденсированные среды и межфазные границы, 2016, т. 18, № 4, с. 568-577.

3. Долгих И. И., Тяпкина В. А., Ковалева Т. А., Битюцкая Л. А. // Конденсированные среды и межфазные границы, 2016, т. 18, № 4, с. 505-512.

4. Герасименко А. Ю., Ичкитидзе Л. П., Савельев М. С., Светличный В. А., Подгаецкий В. М. // Нанотехника, 2013, № 3(35), с. 99-104.

5. Подгаецкий В. М., Герасименко А. Ю., Савельев М. С., Бобринецкий И. И., Терещенко С. А., Селищев С. В., Светличный В. А. // Известия академии инженерных наук им. А.М. Прохорова, 2015, № 2, с. 1538.

6. Благов Е. В., Герасименко А. Ю., Дудин А. А., Ичкитидзе Л. П., Кицюк Е. П., Орлов А. П., Павлов А. А., Полохин А. А., Шаман Ю. П. // Медицинская техника, 2015, № 5, c. 25-28.

7. Ma R. Z., Wei B. Q., Xu C. L., Liang J., Wu D. H. // Carbon, 2000, vol. 38, № 4, pp. 623-641.

8. Sadeghpour H. R., Brian E. // Physica Scripta, 2004, vol. T110, pp. 262-267.

9. Gyorgy E., Perez del Pino A., Roqueta J., Ballesteros B., Cabana L., Tobias G. // J. of Nanoparticle Research, 2013, vol. 15, pp. 1852.

10. Krasheninnikov A. V., Banhart F. // Nature Materials, 2007, vol. 6, pp. 723-733.

11. Ogihara N., Usui Y., Aoki K., Shimizu M., Narita N., Hara K., Nakamura K., Ishigaki N., Takanashi S., Okamoto M., Kato H., Haniu H., Ogiwara N., Nakayama N., Taruta S., Saito N. // Nanomedicine, 2012, vol. 7, № 7, pp 981993.

12. Abarrategi A., Gutiérrez M. C., Moreno-Vicente C., Hortigüela M. J., Ramos V., Lypez-Lacomba J. L., Fer- 
rer M. L., del Monte F. // Biomaterials, 2008, vol. 29, № 1, pp. $94-102$.

13. Newman P., Minett A., Ellis-Behnke R., Zreiqat H. // Nanomedicine, 2013, vol. 9, № 8, pp. 1139-1158.

14. Sahithi K., Swetha M., Ramasamy K., Selvamurugan N. // International journal of Biological Macromolecules, 2010, vol. 46, № 3. pp. 281-283.

15. Pan L., Pei X., He R., Wan Q., Wang J. // Colloids and Surfaces B: Biointerfaces 2012, vol. 93, pp. 226-234.

16. Mattioli-Belmonte M., Vozzi G, Whulanza Y., Seggiani M., Fantauzzi V., Orsini G., Ahluwalia A. // Materials Science and Engineering: C, 2012, vol. 32, № 2, pp. 152159.

17. Venkatesan J., Qian Z., Ryu B., Kumar N. A., Kim S. // Carbohydrate Polymers, 2011, vol. 83, № 2. pp. 569-577.

18. Lin C., Wang Y., Lai Y., Yang W., Jiao F., Zhang H., Shefang Ye., Zhang Q. // Colloids and Surfaces B: Biointerfaces, 2011, vol. 83, № 2, pp. 367-375.

19. Venkatesan J., Ryu B., Sudha P. N., Kim S. // International Journal of Biological Macromolecules, 2012, vol. 50, № 2, pp. 393-402.

20. Sitharaman B. Shi X., Walboomers X. F., Liao H., Cuijpers V., Wilson L. J., Mikos A. G., Jansen J. A. // Bone, 2008. vol. 43, № 2, pp. 362-370.
21. 21. Barrientos-Durán A., Carpenter E. M., Nieden N. I., Malinin T. I., Rodríguez-Manzaneque J. C., Zanello L. P. // International journal of Nanomedicine, 2014, vol. 9, pp. 42774291.

22. Siqueira I.A., Corat M. A., Cavalcanti B., Ribeiro Neto W. A., Martin A. A., Bretas R. E., Marciano F. R., Lobo A. O. // ACS Applied Materials \& Interfaces, 2015, vol. 7, № 18, pp. 9385-9398.

23. Bleustein C. B., Felsen D., Poppas D. P. // Lasers in Surgery and Medicine, 2000, vol. 27(2), pp. 82-86.

24. Bujacz A. // Acta Crystallographica Section D, 2012, vol. D68, pp. 1278-1289.

25. Che J., Cagin T., Goddard W. A. // Nanotechnology, 2000, vol. 11, pp. 65-69.

26. Bettinger H. F. // J. Phys. Chem. B, 2005. vol. 109, № 15 , pp. 6922-6924.

27. Brenner D. W., Shenderova O. A., Harrison J. A. // J. Phys.: Condens. Matter, 2002, vol. 14, № 4, pp. 783802.

28. Elstner M., Porezag D., Jungnickel G., Elsner J., Haugk M., Frauenheim Th., Suhai S., Seifert G. // Phys. Rev. B, 1998, vol. 58, № 11, pp. 7260-7268.

29. Ten G. N., Nechaev V. V., Shcherbakov R. S. Baranov V. I. // J. Struct. Chem., vol. 51, № 1, pp. 32-39.

\title{
LASER STRUCTURING OF THE CARBON NANOTUBES ENSEMBLE INTENDED TO FORM BIOCOMPATIBLE ORDERED COMPOSITE MATERIALS
}

\author{
CC2017 A. Yu. Gerasimenko \\ National Research University of Electronic Technology (MIET), Bld. 1, Shokin sq., Zelenograd, \\ 124498 Moscow, Russia, \\ e-mail: gerasimenko@bms.zone
}

Received 04.08.2017

\begin{abstract}
The article presents the results of the creation of composite materials. Laser irradiation in the near infrared region $(970 \mathrm{~nm})$ of water-albumin dispersion of single-layer carbon nanotubes (SLCNT) is characterised by an intensive absorption of radiation, which is accompanied by nanotube heating. Significant warming occurs at the ends of nanotubes and in the areas of localised defects where the thermal conductivity is significantly reduced. In terms of chemical reaction, the open ends of nanotubes and areas with defects appear to be most active, thus, the idea of splicing SLCNT in the defective areas was taken as the basis. Numerical simulation showed that the process of nanotube matching in the frame starts when the laser heats to a temperature of $80-100^{\circ} \mathrm{C}$. This process occurs within a few nanoseconds. The graphs of enthalpy allow us to conclude that the process of SLCNT frame forming with four defects in the form $1 \mathrm{~V}$ (single carbon atom vacancies) present in the region of the tube junctions results in the greatest energetic advantage.

In composite materials, the bonding of SLCNT with albumin molecules occurs though the Glu and Asp amino acid residues. The interaction energy between the nanotube frame and the albumin matrix is up to $580 \mathrm{~kJ} / \mathrm{mol}$.

Molecular dynamic simulations show that an increase in the number of oxygen atoms leads to a decrease in the interaction energy between SLCNT and albumin. The attachment of the oxygen atoms
\end{abstract}




\section{А. Ю. ГЕРАСИМЕНКО}

to the SLCNT leads to the distortion of nanotubes, which increases with the increase in the number of oxygen atoms. The change of the attachment points of the oxygen atom to the nanotube oxygen atoms allows configuring the desired shape of the nanotube frame in the albumin matrix.

Composite materials based on SLCNT water-albumin dispersion have a developed surface with periodic peaks and troughs. This can be seen from the atomic force microscopy images and is associated with the carbon nanotube framework which is formed under laser radiation. The pore size ranges between 30-120 nm.

Composite materials can provide superior adhesion of cells planted on their surface. It can be used as a tissue-engineered matrix to restore three-dimensional structure of bone and connective tissue.

Keywords: laser radiation, structuring, framework, carbon nanotubes, defects, composite materials, albumin, biocompatibility.

\section{ACKNOWLEDGEMENTS}

The author is grateful to theprofessor, Dr. Sc.(Phys.Math.) Podgaetsky V. M. and the scientific team of the Department of Biomedical Systems MIETfor assistance in carrying out experimental work and discussing the results, as well as the scientific team of the professor, Dr. Sc.(Phys.-Math.) Glukhova O.E. for assistance in conducting theoretical studies, including using the software product KVAZAR (www.nanokvazar.ru).

This work was supported by the grant of the President of the Russian Federation dated 22 February, 2017 (grant no 14.Y30.17.1328-MK).

\section{REFERENCES}

1. Eleckii A. V. Advances in Physical Sciences [Uspekhi fizicheskhih nauk], 1997, vol. 167, no. 9, pp. 945-972. DOI: http://dx.doi.org/10.3367/UFNr.0167.199709b.0945

2. Tuchin A. V., Tyapkina V. A., Bityutskaya L. A., Bormontov E. N. Condensed Matter and Interphase, 2016, vol. 18 , no. 4 , pp. 568-577. Available at: http://www.kcmf. vsu.ru/resources/t_18_4_2016_015.pdf (in Russian)

3. Dolgikh I. I., Tyapkina V. A., Kovaleva T. A., Bityutskaya L. A. Condensed Matter and Interphase, 2016, vol. 18, no. 4, pp. 505-512. Available at: http://www.kcmf.vsu.ru/ resources/t_18_4_2016_007.pdf (in Russian)

4. Gerasimenko A. Yu., Ichkitidze L. P., Savel'ev M. S., Svetlichnii V. A., Podgaetskii V. M. Nanotechnics, 2013, no. 3(35), pp. 99-104. (in Russian)

5. Podgaetskii V. M., Gerasimenko A. Yu., Savel'ev M. S., Bobrineckii I. I., Tereshchenko S. A., Selishchev S. V., Svetlichnii V. A. News Academy of Engineering Sciences A. M. Prokhorov, 2015, no. 2, pp. 15-38. (in Russian)

6. Blagov E. V., Gerasimenko A. Yu., Dudin A. A., Ichkitidze L. P., Kitsyuk E. P., Orlov A. P., Pavlov A. A., Polohin A. A., Shaman Yu. P. Biomedical Engineering, 2016, vol. 49, no. 5, pp. 288-291. DOI 10.1007/s10527-016-9550-1

7. Ma R. Z., Wei B. Q., Xu C. L., Liang J., Wu D. H. Carbon, 2000, vol. 38, no. 4, pp. 623-641. https://doi. org/10.1016/S0008-6223(00)00008-7

8. Sadeghpour H. R., Brian E. Physica Scripta, 2004, vol. T110, pp. 262-267. https://doi.org/10.1238/Physica. Topical.110a00262
9. Gyorgy E., Perez del Pino A., Roqueta J., Ballesteros B., Cabana L., Tobias G. J. of Nanoparticle Research, 2013, 15:1852. DOI 10.1007/s11051-013-1852-6

10. Krasheninnikov A. V., Banhart F. Nature Materials, 2007, vol. 6, pp. 723-733. doi:10.1038/nmat1996

11. Ogihara N., Usui Y., Aoki K., Shimizu M., Narita N., Hara K., Nakamura K., Ishigaki N., Takanashi S., Okamoto M., Kato H., Haniu H., Ogiwara N., Nakayama N., Taruta S., Saito N. Nanomedicine, 2012, vol. 7, no. 7, pp. 981-993. DOI:10.2217/nnm.12.1

12. Abarrategi A., Gutiérrez M. C., Moreno-Vicente C., Hortigüela M. J., Ramos V., Lypez-Lacomba J. L., Ferrer M. L., del Monte F. Biomaterials, 2008, vol. 29, no. 1, pp. 94-102. DOI:10.1016/j.biomaterials.2007.09.021

13. Newman P., Minett A., Ellis-Behnke R., Zreiqat H. Nanomedicine, 2013, vol. 9, no. 8, pp. 1139-1158. DOI:10.1016/j.nano.2013.06.001

14. Sahithi K., Swetha M., Ramasamy K., Selvamurugan N. International Journal of Biological Macromolecules, 2010, vol. 46, no. 3. pp. 281-283. https://doi.org/10.1016/ j.ijbiomac.2010.01.006

15. Pan L., Pei X., He R., Wan Q., Wang J. Colloids and Surfaces B: Biointerfaces 2012, vol. 93, pp. 226-234. https://doi.org/10.1016/j.colsurfb.2012.01.011

16. Mattioli-Belmonte M., Vozzi G, Whulanza Y., Seggiani M., Fantauzzi V., Orsini G., Ahluwalia A. Materials Science and Engineering: C, 2012, vol. 32, no. 2, pp. 152159. https://doi.org/10.1016/j.msec.2011.10.010

17. Venkatesan J., Qian Z., Ryu B., Kumar N. A., Kim S. Carbohydrate Polymers, 2011, vol. 83, no. 2. pp. 569-577. https://doi.org/10.1016/j.carbpol.2010.08.019

18. Lin C., Wang Y., Lai Y., Yang W., Jiao F., Zhang H., Shefang Ye., Zhang Q. Colloids and Surfaces B: Biointerfaces, 2011, vol. 83, no. 2, pp. 367-375. https://doi. org/10.1016/j.colsurfb.2010.12.011

19. Venkatesan J., Ryu B., Sudha P. N., Kim S. International Journal of Biological Macromolecules, 2012, vol. 50, no. 2, pp. 393-402. https://doi.org/10.1016/j. ijbiomac.2011.12.032

20. Sitharaman B. Shi X., Walboomers X. F., Liao H., Cuijpers V., Wilson L. J., Mikos A. G., Jansen J. A. Bone, 2008. vol. 43, no. 2, pp. 362-370. DOI:10.1016/j. bone.2008.04.013 
21. Barrientos-Durán A., Carpenter E. M., Nieden N. I., Malinin T. I., Rodríguez-Manzaneque J. C., Zanello L. P. International Journal of Nanomedicine, 2014, vol. 9, pp. 42774291. DOI:10.2147/IJN.S62538

22. Siqueira I. A., Corat M. A., Cavalcanti B., Ribeiro Neto W. A., Martin A. A., Bretas R. E., Marciano F. R., Lobo A. O. ACS Applied Materials \& Interfaces, 2015, vol. 7, no. 18, pp. 9385-9398. DOI:10.1021/acsami.5b01066

23. Bleustein C. B., Felsen D., Poppas D. P. Lasers in Surgery and Medicine, 2000, vol. 27(2), pp. 82-86.

24. Bujacz A. Acta Crystallographica Section D, 2012, vol. D68, pp. 1278-1289. DOI:10.1107/S09074449 12027047
25. Che J., Cagin T., Goddard W. A. Nanotechnology, 2000, vol. 11, pp. 65-69.

26. Bettinger H. F. J. Phys. Chem. B, 2005. vol. 109, no. 15, pp. 6922-6924. DOI: 10.1021/jp0440636

27. Brenner D. W., Shenderova O. A., Harrison J. A. J. Phys.: Condens. Matter, 2002, vol. 14, no. 4, pp. 783-802. https://doi.org/10.1088/0953-8984/14/4/312

28. Elstner M., Porezag D., Jungnickel G., Elsner J., Haugk M., Frauenheim Th., Suhai S., Seifert G. Phys. Rev. $B$, 1998, vol. 58, no. 11, pp. 7260-7268. DOI: https://doi. org/10.1103/PhysRevB.58.7260

29. Ten G. N., Nechaev V. V., Shcherbakov R. S. Baranov V. I. J. Struct. Chem., vol. 51, no. 1, pp. 32-39. DOI: https://doi.org/10.1007/s10947-010-0005-3
Герасименко Александр Юрьевич - к. ф.-м. н., доцент, Национальный исследовательский университет «МИЭТ»; тел.: +7(926) 7029778, e-mail: gerasimenko@ bms.zone
Gerasimenko Alexander Yu. - Cand. Sci. (Phys.-Math.), Associate Professor, National Research University of Electronic Technology MIET, ph.: +7(926) 7029778, e-mail: gerasimenko@bms.zone 